\title{
POLYNEURITIS IN HAEMOCHROMATOSIS
}

\author{
EDWARD JaRRETT, M.D., M.R.C.P. \\ Consultant Physician, Dorset County Hospital, Dorchester, Dorset
}

\author{
ANTONy BarTer, M.B., D.Obst.R.C.O.G. \\ General Practitioner, Bridport, Dorset
}

\section{Case Report}

A male taxi-driver, aged forty-seven, was admitted to the Dorset County Hospital on 7.9.60. He was a diabetic of five years standing on $180 \mathrm{~g}$. of carbohydrate and 80 units of lente insulin daily. Following an attack of diarrhoea and vomiting he gave a five days' history of increasing weakness in the legs.

Examination. He was thin, slightly icteric, with sparse axillary and pubic hair, small atrophic testes and multiple pigmented needle-track marks on the lower abdomen and thighs. The liver was large and hard, and the spleen just palpable. He had a flaccid weakness of both legs with tender muscles and absent knee and ankle jerks. This subsequently developed into a frank paraplegia. There were no sensory changes during the early stages.

Investigations. Blood count: $\mathrm{Hb} 88 \%$, $\mathrm{MCHC} 36 \%$, PCV $36 \mathrm{~mm}$., ESR $12 \mathrm{~mm}$. (Wintrobe). Icteric Index 20 units, wbc 12,900 (neutrophils $75 \%$, monocytes $9 \%$, lymphocytes $16 \%$, marked toxic changes in the neutrophils). Prothrombin time $50 \%$ of normal. The blood culture grew $E$. Coli.

The serum iron was $440 \mu \mathrm{g} . / 100 \mathrm{ml}$., the S.G.P.T. was 372 units, and the serum bilirubin $2.9 \mathrm{mg}$. $/ 100 \mathrm{ml}$., (direct $1.3 \mathrm{mg} . / 100 \mathrm{ml}$.). The total protein was $5.7 \mathrm{~g}$. / $100 \mathrm{ml}$., of which the albumin was markedly decreased and the alpha-2 and gamma globulin increased. The CSF was slightly xanthrochromic; there were 34 wbcs (mainly polymorphonuclears), and the protein was $15^{\circ}$ $\mathrm{mg}$./100 ml. A diagnosis of hæmochromatosis and acute polyneuritis was made.

Progress and Treatment. His temperature rose to
102. $5^{\circ} \mathrm{F}$ and his pulse to $150 / \mathrm{min}$. and there were signs of early meningitis. He was treated with prednisolone in high dosage, chloramphenicol and later tetracycline. His condition deteriorated, and he died on 24.9.60.

Autopsy Report. There were bilateral pleural effusions. The liver was enlarged and weighed $1,652 \mathrm{~g}$.; it was very firm and showed irregular cirrhosis; there were one or two small abscesses. The spleen was enlarged, weighing $364 \mathrm{~g}$. It was firm, and on section showed decreased prominence of the follicles. The pancreas was firm and slatey-grey in colour. There was a turbid ascites present. Histology showed heavy deposits of iron in the cardiac muscle and slight deposition in the zona glomerulosa of the adrenal cortex, the pars anterior of the pituitary gland and in the dermis at the site of previous insulin injections. There was no histological abnormality found in the spinal cord, but the peripheral nerves were not examined. The pathologist's cause of death was:-
(i) heart failure,
(ii) E. coli septicæmia,
(iii) hæmochromatosis.

\section{Comment}

A striking sign which we have not seen reported elsewhere was the pigmentation along the injection tracks. The rapid progression of the polyneuritis was quite unlike that normally met with in diabetic neuropathy. After reading Melnick and Whitfield's paper (1962) we feel that there is a possibility of a direct link between the polyneuritis and the hæmochromatosis.

\section{REFERENCE}

Melnick, S. C., and Whitfield, A. G. W. (1962): Polyneuritis in Hæmochromatosis, Postgrad. med. F., 38, 580.

\section{CONGENITAL PENILE SINUS}

\author{
Christopher WASTel, F.R.C.S. \\ Department of Surgery, Westminster Hospital
}

A ventral mid-line sinus of the penis is an unusual condition resulting, possibly, from a failure of fusion of the urethral crests. It is related to the more commonly occurring mid-line congenital cyst and nearly 50 examples of these two anomalies have been reported to date (Thompson, 1959).

\section{Case Report}

A 43-year-old circumcised man sought advice about two superficial sore lesions on the under surface of his penis and scrotum. These had been present for two weeks and had discharged a small quantity of pus. Seven years previously he had noticed a pore on his penis from which it was possible to express a chalky material. At this time his doctor had incised a superficial infective lesion close by this orifice. On examining the penis and scrotum (Figs. I and 2) there were two mid-line infected lesions, one being at the peno-scrotal junction and the other $5 \mathrm{~cm}$. posterior to it. In addition there were two sinuses, one, $2 \mathrm{~cm}$. in length, extended along the proximal third of the shaft of the penis from an orifice situated in 


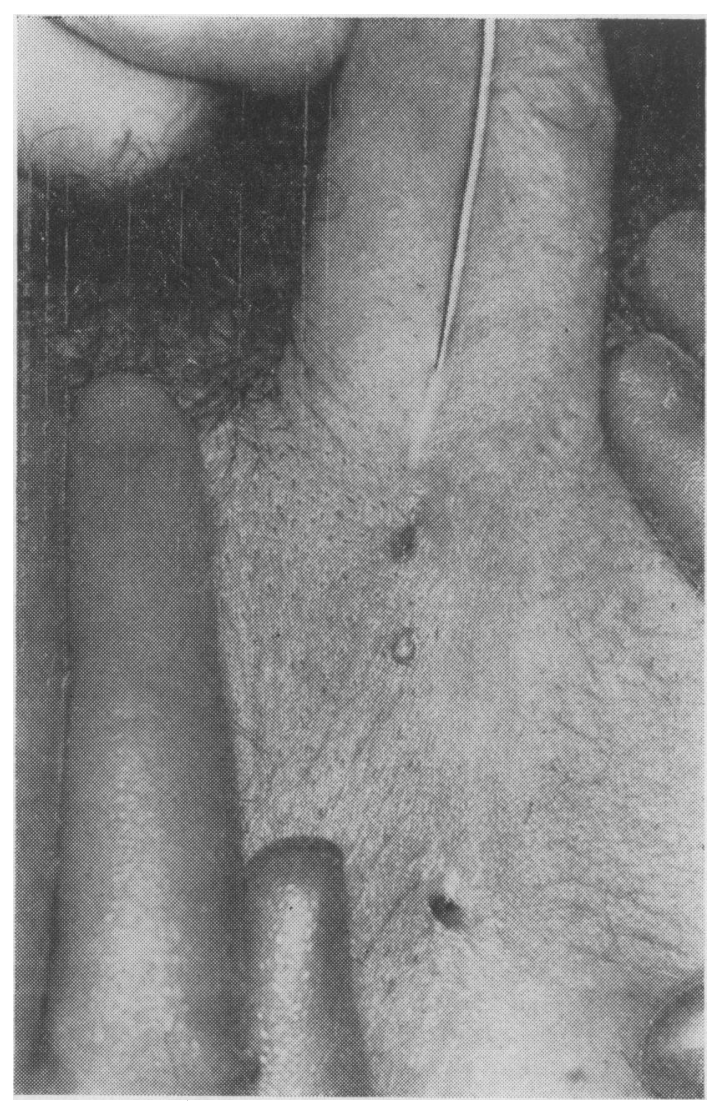

Fig. 1.-Showing the sinus at the peno-scrotal junction.

the mid-line just proximal to the peno-scrotal junction. The other, $12 \mathrm{~cm}$. in length, extended from a similar pore in the central part of the scrotum to just in front of the anus. Probing revealed that both sinuses terminated blindly and had no communication with the urethra, each other, or the superficial infective lesions.

Each sinus was palpable deep to the mid-line raphe as a firm, non-tender cord. On general clinical examination there was no evidence of other congenital anomalies. There was no history of veneral disease and the WR and GCFT were both negative. Culture of pus from the infective lesions grew only staphylococcus albus.

Under general anæsthetic the sinuses were laid open with scissors and their deep aspects were seen to consist of pink mucous membrane. The slit thus produced healed rapidly during the next seven days with no treatment other than dressings.

Biopsy of the posterior of the two sinuses showed it to be lined by a modified type of stratified squamous epithelium. (Fig. 3.)

\section{Discussion}

The existence of ventral mid-line peno-scrotal cysts and sinuses is embryologically determined. The urethra, apart from the balanitic portion, is formed in endoderm derived from the epithelium lining the urogenital sinus. The endodermal core of cells is enclosed beneath the skin surface of the

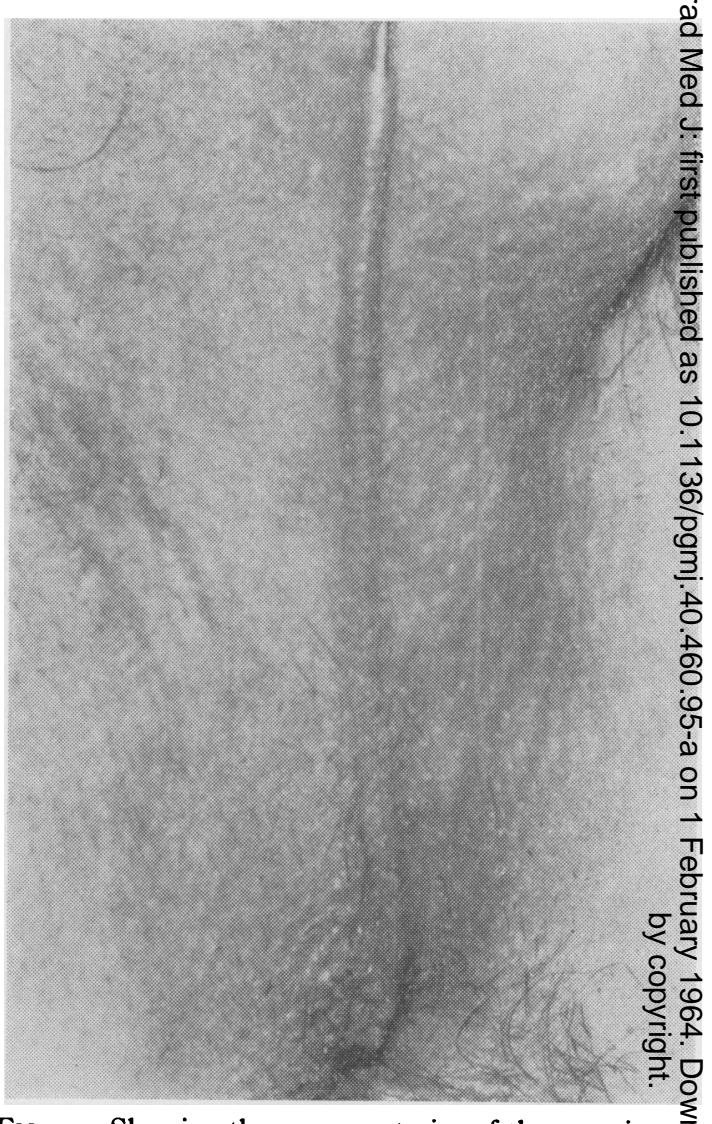

FIG. 2.-Showing the more posterior of the two sinuse with a probe passed along its entire length. The th of the probe is just anterior to the anus.

phallus by the fusion over it of the urethral crestș This leaves a mid-line and persistent ventral raphe which extends from the frenum of the penis to just in front of the anus. The balanitic portion of the urethra is formed by a downgrowth of ectoderma cells from the urethral plate (Glenister, 1958).

has been suggested that incomplete closure of the urethral crests may result in ectodermal cells being left deep to the skin surface and these later produce a cyst or a sinus. A second theory is that after the fusion of the urethral crest is complete outgrowths of embryonic epithelium split off and later canalize

It is interesting to note that the majority of cases: reported in detail have not presented until betweew the ages of 20 and 30 , although there are exceptionso Neff (1936) reported a sinus in a 13-year-old boye which became infected, and also a cyst in a man of 68 which had remained unchanged since boyhood Commonly a patient with this anomaly will firso consult the venereologist and although it is usuall only involved by non-venereal types of infection is well to remember that it may in fact harbour of gonococcus (Rupel, 1924).

The diagnosis may usually be made by inspectio 


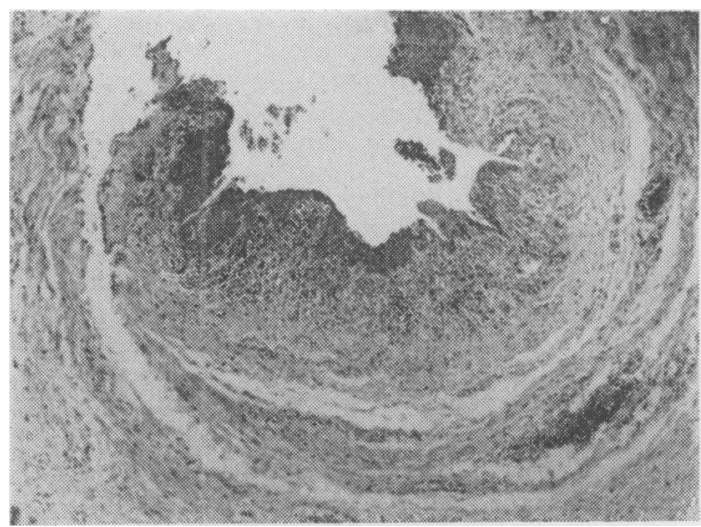

FIG. 3.-A microphotograph of a section, stained with hæmatoxylin and eosin, of the posterior sinus. The sinus is lined by a modified type of stratified squamous epithelium.

aided by probing. The differential diagnosis however includes the primary chancre of syphilis, chan- croid, granuloma venereum, tuberculous sinuses, infected sebaceous cysts and the very rare pilonidal cyst of the perineum (Woolridge, 1955). The sinuses under discussion have no communication with the urethra and so may be distinguished from hypospadias and urethral fistulæ secondary to some other urethral pathology.

On section, the sinuses are lined by stratified epithelium, while on the other hand cysts may be lined either by stratified squamous or columnar epithelium.

Various methods of treatment have been employed but in this case simple laying open of the sinus was speedily effective.

\section{Summary}

A case of ventral peno-scrotal sinus is described. Its embryology, differential diagnosis and treatment are discussed.

I would like to thank Professor H. Ellis for helpful advice and for allowing me to publish this case, Dr. I. Dawson who prepared and reported on the histology, and also the Photographic Department of the Westminster Hospital.

\title{
REFERENCES
}

Glenister, T. W. (1958): A Correlation of the Normal and Abnormal Development of the Penile Urethra and Infraumbilical Abdominal Wall, Brit. F. Urol., 30, I 17.

NefF, J. H. (1936): Congenital Canals and Cysts of the Genito-perineal Raphe, Amer. F. Surg., 31, 308.

RUPEL, E. (1924): Epidermal Canals Infected with Gonococci, Surg. Gynec. Obstet., 39, 636.

Thompson, S. G. (1959): Congenital Skin Sinus of the Penis; Report of a Case, Brit. $\mathcal{F}$. Surg., 47, 290.

Woolridge, W. E. (1955): Congenital Anomalies of the Median Raphe, Arch. Derm. Syph., 71, 713.

\section{PNEUMOCOCCAL MENINGO-ENCEPHALITIS}

\section{An Unusual Case}

\author{
J. H. Mitchell, M.B., M.R.C.P.(Ed.), M.R.C.P.(Glasg.), D.Obst.R.C.O.G. \\ Registrar, Infectious Diseases Unit, Gateside Hospital, Greenock
}

\begin{abstract}
PNEUmococcal meningitis has always a poor prognosis. This particular case is interesting for two reasons: firstly, although it seemed at one time that recovery would be very limited, in fact it was remarkably complete; and secondly, there were, during the latter part of the illness, some unusual neurological features.
\end{abstract}

\section{Case Report}

The patient, a male aged 40 years, was admitted on January I I, 1962. There was no history of skull trauma. About two weeks prior to admission he had had a mild respiratory illness for which his general practitioner prescribed oxytetracycline. Recovery was satisfactory, but he had not yet returned to work, when on January II, he became suddenly fevered and confused and complained of intense headache.

On Admission. The patient was confused and drowsy.
Temperature $98.8^{\circ} \mathrm{F}$., rising rapidly to $103^{\circ} \mathrm{F}$, pulse rate $80 / \mathrm{min}$., B.P. $100 / 70 \mathrm{~mm}$. Hg. Cardio-vascular system, lung fields and ear drums normal.

CNS: marked meningeal irritation with moderate dysphasia, particularly manifest as spoonerisms. Normal optic fundi and pupils. Left-sided facial weakness of supranuclear type. Tendon reflexes and plantar responses normal.

CSF : increased pressure, positive Pandy reaction, cells $325 / \mathrm{cu}$. mm., mainly polys.; protein $130 \mathrm{mg}$.; sugar $70 \mathrm{mg}$., chloride $630 \mathrm{mg}$./ $100 \mathrm{ml}$.; there were abundant encapsulated Gram-positive diplococci, mainly extracellular, which were confirmed on culture as being pneumococci, sensitive to all routine antibiotics.

A diagnosis of pneumococcal meningitis was made and treatment begun with benzylpenicillin, $(20,000$ U. intrathecally daily, I megaunit 4-hourly i.m.) and sulphathiazole (r.5 g. then I g. 4-hourly i.m.). 